\title{
Weight Gain: A Modifiable Risk Factor for Primary Cesarean Delivery
}

\author{
Annelee Boyle ${ }^{*}$, Julia Timofeev², Sameer Desale3, Rita W. Driggers², Donald J. Dudley ${ }^{4}$ \\ ${ }^{1}$ Department of Obstetrics and Gynecology, MedStar Washington Hospital Center, Washington DC, USA \\ ${ }^{2}$ Department of Gynecology and Obstetrics, Johns Hopkins University School of Medicine, Baltimore, MD, USA \\ ${ }^{3}$ MedStar Health Research Institute, Hyattsville, MD, USA \\ ${ }^{4}$ Department of Obstetrics and Gynecology, University of Virginia School of Medicine, Charlottesville, VA, USA \\ Email: *ab9cd@virginia.edu
}

How to cite this paper: Boyle, A., Timofeev, J., Desale, S., Driggers, R.W. and Dudley, D.J. (2017) Weight Gain: A Modifiable Risk Factor for Primary Cesarean Delivery. Open Journal of Obstetrics and Gynecology, 7, 525-531.

https://doi.org/10.4236/ojog.2017.75055

Received: April 11, 2017

Accepted: May 20, 2017

Published: May 23, 2017

Copyright () 2017 by authors and Scientific Research Publishing Inc. This work is licensed under the Creative Commons Attribution International License (CC BY 4.0).

http://creativecommons.org/licenses/by/4.0/

\begin{abstract}
Objective: To evaluate the relationship between weight gain and primary cesarean delivery. Methods: This was a retrospective cohort study of women 5442 who delivered a singleton from 2009-2013. Women were classified as normal weight [pre-pregnancy body mass index (BMI) $18.5-24.9 \mathrm{~kg} / \mathrm{m}^{2}$ ], overweight (pre-pregnancy BMI $25.0-29.9 \mathrm{~kg} / \mathrm{m}^{2}$ ), obese (pre-pregnancy BMI $30.0-39.9 \mathrm{~kg} / \mathrm{m}^{2}$ ), and extremely obese (pre-pregnancy BMI $\geq 40.0$ $\mathrm{kg} / \mathrm{m}^{2}$ ). Each BMI group was subdivided by weight gain-low, recommended, or excessive, as defined by the 2009 Institute of Medicine guidelines-and rates of primary cesarean delivery were compared. Results: The overall primary cesarean delivery rate was $27.3 \%$, but this varied based on pre-pregnancy BMI. The primary cesarean delivery rate among women of normal weight was $22.3 \%$, overweight women $27.5 \%$, obese women $35.3 \%$, and extremely obese women $45.7 \%$. Among normal-weight, obese, and extremely obese women, the risk of primary cesarean delivery increased with excessive weight gain [normal weight odds ratio (OR) 1.63, (95\% confidence interval 1.32 - 2.01); obese OR 1.55 (1.12 - 2.15); extremely obese OR 2.19 (1.18 - 4.08)] compared to recommended weight gain. More than half of women (53.2\%) had excessive weight gain. Conclusion: Adherence to guidelines may decrease a woman's risk of primary cesarean delivery.
\end{abstract}

\section{Keywords}

Primary Cesarean, Weight Gain, Pre-Pregnancy BMI, Obese, Obesity

\section{Introduction}

Cesarean delivery is among the most common major surgical procedure performed worldwide, with an estimated 18.5 million performed yearly [1]. The to- 
tal cesarean delivery rate has risen dramatically over the last two decades, especially in high- and middle-income countries [2]. As early as 1985, a panel of international experts at a meeting organized by the World Health Organization (WHO) stated "there is no justification for any region to have a rate higher than $10 \%-15 \%$," a sentiment echoed in their 2015 statement [2]. Yet, in 2010, 69 of 137 countries studied had a cesarean delivery rate greater than $15 \%$ [1]. The most recent cesarean delivery rate in the United States was 32.7 [3], while in England it was 26.2\% [4]. Mirroring the rise in the total cesarean delivery rate, the primary cesarean delivery rate has also increased. Avoiding primary cesarean deliveries could decrease total cesarean delivery rate both directly (in the index pregnancy) and indirectly (by avoiding repeat cesarean deliveries).

While many factors have been cited for the rise in cesarean deliveries, prepregnancy weight and weight gain during pregnancy are among the few factors that are potentially within a woman's control. Both obesity and excessive weight gain have been linked to an increased risk of cesarean delivery; however, much of the data include women with a history of prior cesarean delivery [5] [6].

The objective of this study was to evaluate the relationship between prepregnancy body mass index (BMI), weight gain during pregnancy, and the risk of primary cesarean delivery. Our hypothesis was that excessive weight gain during pregnancy would be associated with an increased risk of primary cesarean delivery, regardless of pre-pregnancy BMI. The primary outcome was cesarean delivery rate among women with a normal pre-pregnancy BMI (18.5 - 24.9 $\mathrm{kg} / \mathrm{m}^{2}$ ) who gained more weight than recommended by the Institute of Medicine as compared to weight gain within guidelines.

\section{Methods}

We conducted a retrospective cohort study of women who delivered from 2009 to 2012 at a single tertiary care center with active physician and midwife practices. The intuition does approximately 3500 deliveries per year and has approximately 20 attending physicians and 7 midwives on staff. Women were included if they delivered a singleton pregnancy at 23 weeks' gestation or above and had in the records a measured or self-reported height, pre-pregnancy weight, and weight at time of admission to labor and delivery. Women were excluded if they had a prior cesarean delivery. Only 4 patients were underweight prior to conception; they were excluded from the analysis as their numbers were too few to allow for a valid analysis. Labor and delivery records were abstracted by one of two trained research nurses who were blinded to the study's objective and hypothesis. The local institutional review board (IRB) approved this study (IRB \#2012-259).

Women were classified as normal weight [pre-pregnancy body mass index (BMI) $18.5-24.9 \mathrm{~kg} / \mathrm{m}^{2}$ ], overweight (pre-pregnancy BMI $25.0-29.9 \mathrm{~kg} / \mathrm{m}^{2}$ ), obese (pre-pregnancy BMI $30.0-39.9 \mathrm{~kg} / \mathrm{m}^{2}$ ), or morbidly obese (pre-pregnancy BMI $\geq 40.0 \mathrm{~kg} / \mathrm{m}^{2}$ ). Each BMI group was subdivided by weight gain: low, recommended, or excessive weight as defined by the 2009 Institute of Medicine 
guidelines [7]. Weight gain was measured by subtracting pre-pregnancy weight from current weight. Most often these were the weights at the first and last prenatal visits. Women who gained the recommended amount of weight based on their pre-pregnancy BMI (25 - 35 pounds for those of normal weight, 15 - 25 pounds for those who were overweight, and $11-20$ pounds for those who were obese or extremely obese) served as controls. Missing data was excluded from analysis.

In order to detect a $33 \%$ increase in primary cesarean delivery rate (assuming a baseline risk of 24\%) with a two-sided significance of 95 and a power of 80 , we calculated a sample size of 1980 was needed for our primary outcome. All analyses were performed using SAS version 9.1.3 (SAS Institute, Inc., Cary, NC). Chi-square, Kruskal-Wallis, or Student's t-test were used where appropriate, with a p-value of $<0.05$ considered statistically significant.

\section{Results}

The study cohort included 5442 women; $0.07 \%$ (4) were underweight, $48.5 \%$ (2639) were normal weight, 26.7\% (1450) were overweight, 20.1\% (1095) were obese, and $4.7 \%$ (254) were extremely obese prior to pregnancy. The underweight women were not included in this analysis. Women with a higher prepregnancy BMI were more likely to be older, African American, and multiparous (Table 1).

Table 1. Demographics and outcomes.

\begin{tabular}{|c|c|c|c|c|c|}
\hline & $\begin{array}{c}\text { Normal Weight } \\
\left(\text { BMI } 18.5-24.9 \mathrm{~kg} / \mathrm{m}^{2}\right) \\
\mathrm{n}=2639\end{array}$ & $\begin{array}{c}\text { Overweight } \\
\left(\text { BMI } 25.0-29.9 \mathrm{~kg} / \mathrm{m}^{2}\right) \\
\mathrm{n}=1450\end{array}$ & $\begin{array}{c}\text { Obese } \\
\left(\text { BMI } 30.0-39.9 \mathrm{~kg} / \mathrm{m}^{2}\right) \\
\mathrm{n}=1095\end{array}$ & $\begin{array}{c}\text { Extremely Obese } \\
\left(\mathrm{BMI} \geq 40.0 \mathrm{~kg} / \mathrm{m}^{2}\right) \\
\mathrm{n}=254\end{array}$ & $p$ value \\
\hline $\begin{array}{l}\text { Age, years } \\
\text { Mean (SD) }\end{array}$ & $24.8(6.5)$ & $26.4(6.7)$ & $27.2(6.6)$ & $27.9(6.2)$ & $<0.01$ \\
\hline Race & & & & & \\
\hline $\begin{array}{l}\text { White } \\
\text { n (\%) }\end{array}$ & $230(8.7 \%)$ & $171(11.8 \%)$ & $72(6.6 \%)$ & $5(1.9 \%)$ & \\
\hline $\begin{array}{c}\text { AA } \\
\text { n (\%) }\end{array}$ & $1849(70.0 \%)$ & $940(64.8 \%)$ & $805(73.5 \%)$ & $210(82.7 \%)$ & \\
\hline $\begin{array}{l}\text { Hispanic } \\
\mathrm{n}(\%)\end{array}$ & $259(9.8 \%)$ & $158(10.9 \%)$ & $107(9.8 \%)$ & $19(7.5 \%)$ & \\
\hline $\begin{array}{l}\text { Other } \\
\mathrm{n}(\%)\end{array}$ & $301(11.4 \%)$ & $181(12.5 \%)$ & $111(10.1 \%)$ & $20(7.9 \%)$ & $<0.01$ \\
\hline $\begin{array}{c}\text { Gestational Age, w } \\
\text { Mean (SD) }\end{array}$ & $37.8(4.2)$ & $38.7(3.1)$ & $38.8(2.9)$ & $38.4(3.5)$ & $<0.01$ \\
\hline $\begin{array}{c}\text { Multiparous } \\
\mathrm{n}(\%)\end{array}$ & $1219(46.2 \%)$ & 715 (49.3\%) & $639(58.4 \%)$ & $158(62.2 \%)$ & $<0.01$ \\
\hline $\begin{array}{c}1 \text { minute apgar } \\
\mathrm{n}(\%)\end{array}$ & $333(12.6 \%)$ & $120(8.3 \%)$ & $103(9.4 \%)$ & $31(12.2 \%)$ & $<0.01$ \\
\hline $\begin{array}{c}5 \text { minute apgar } \\
\mathrm{n}(\%)\end{array}$ & $129(4.9 \%)$ & $32(2.2 \%)$ & $31(2.8 \%)$ & $6(2.4 \%)$ & $<0.01$ \\
\hline $\begin{array}{l}\text { Birthweight, gn } \\
\text { Mean (SD) }\end{array}$ & $2834(758)$ & $3115(670)$ & 3215 (691) & $3221(778)$ & $<0.01$ \\
\hline $\begin{array}{l}\text { Weight Gain, lb } \\
\text { Mean (SD) }\end{array}$ & $19.2(38.8)$ & $29.6(13.3)$ & $32.6(28.1)$ & $33.0(24.6)$ & $<0.01$ \\
\hline
\end{tabular}


More than half of the women (53.2\%) had excessive weight gain based on current Institute of Medicine guidelines. In the normal-weight cohort, 36\% ( $\mathrm{n}=$ 950) gained the recommended amount of weight, while $40 \%(\mathrm{n}=1056)$ gained more and $24 \%(n=633)$ gained less weight than recommended. In the overweight cohort, $24 \%(\mathrm{n}=348)$ gained the recommended amount, while $65 \%(\mathrm{n}=$ 943) gained more and $11 \%(n=159)$ gained less weight than recommended. In the obese cohort, 20\% $(\mathrm{n}=219)$ gained the recommended amount, while $69 \%(\mathrm{n}$ = 756) gained more and $11 \%(\mathrm{n}=120)$ gained less weight than recommended. In the extremely obese cohort, $23 \%(\mathrm{n}=59)$ gained the recommended amount, while $58 \%(\mathrm{n}=147)$ gained more and $19 \%(\mathrm{n}=48)$ gained less weight than recommended.

Overall, the primary cesarean delivery rate was $27.3 \%$, but this varied based on pre-pregnancy BMI. The primary cesarean delivery rate among women of normal weight was $22.3 \%$, overweight women $27.5 \%$, obese women $35.3 \%$, and extremely obese women $45.7 \%$. The most common indications for cesarean delivery were non-reassuring fetal status, labor arrest, and fetal malpresentation. This was consistent among each cohort.

Among pre-pregnancy normal-weight, obese, and extremely obese women, the risk of primary cesarean delivery increased with excessive weight gain [normal weight odds ratio (OR) 1.63, 95\% confidence interval (CI) $1.32-2.01, p<$ 0.01 ; obese OR $1.55,95 \%$ CI $1.12-2.15, p<0.01$; extremely obese OR $2.19,95 \%$ CI $1.18-4.08, p=0.01$ ] compared to recommended weight gain (Figure 1). Among overweight women, low weight gain was associated with a decreased risk of primary cesarean delivery (OR $0.56,95 \% \mathrm{CI} 0.37-0.94, p=0.02$ ) compared to recommended weight gain. While excessive weight gain was associated with an increase in primary cesarean delivery $(29.2 \%$ vs. $27.3 \%)$ among overweight women, this difference was not statistically significant (OR 1.10, 95\% CI 0.84 -

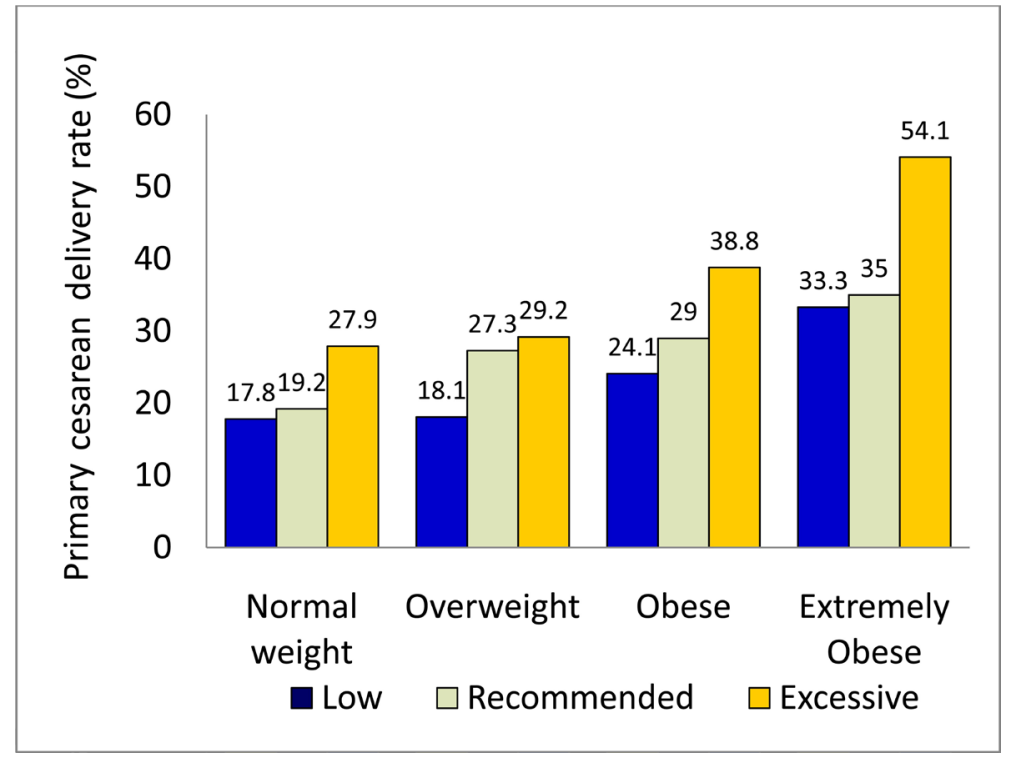

Figure 1. Primary cesarean delivery rate (\%) by weight gained and pre-pregnancy body mass index. 
$1.44, p=0.50)$.

\section{Discussion}

Our study showed that pregnancy weight gain above that recommended by the Institute of Medicine increases risk for primary cesarean delivery, and this was statistically significant for normal weight, obese, and extremely obese patients. In this study, both higher pre-pregnancy BMI and excessive weight gain increased the risk of primary cesarean delivery. However, even among the morbidly obese, more than half of women had a successful vaginal delivery. Thus, morbid obesity itself should not be considered an indication for cesarean delivery.

The reason for the increase in cesarean delivery rate is likely multifactorial. Obese women are less likely to enter spontaneous labor [8], and spontaneous labor confers a lower risk of cesarean delivery [9]. The first stage of labor is longer in obese women compared to their non-obese counterparts [8]. Obese women require higher doses of oxytocin during induction [10]. There are also technical limitations practitioners must consider when managing women in labor and delivery who are overweight or obese. For example, maintaining continuous fetal-heart-tone monitoring becomes more difficult with increasing BMI, and the ability to perform a cesarean quickly for fetal benefit is limited by increasing amounts of adipose tissue [11]. Obese women are also at increased risk for anesthetic complications [12]. These technical issues may prompt physicians to have a lower threshold to perform a cesarean.

In our study, increased pregnancy weight gain in the overweight groups was not associated with a statistically significant increase in cesarean delivery. Perhaps this is because the weight gained in the overweight group was only 4.6 pounds over the Institute of Medicine recommendations as compared to 12.6 pounds for obese and 13.0 pounds for extremely obese groups. This may suggest that weight gain less than 5 pounds over the recommendations does not increase cesarean rate, but more research is needed.

In our cohort, more than half of the women entered pregnancy overweight or obese, which is echoed by US national data [13]. Excessive weight gain as defined by Institute of Medicine guidelines was also common [7], affecting more than $50 \%$ of the study cohort. Despite lower recommended weight-gain ranges, women with higher pre-pregnancy BMIs gained more weight during pregnancy than those who entered pregnancy at a normal weight (Table 1).

Primary cesarean delivery is known to increase a women's risk of complications in both the index pregnancy and subsequent pregnancies [14] [15], and maternal obesity compounds these risks [11]. Previous studies have also linked excessive weight gain in pregnancy to other, non-surgical complications, including hypertensive disorders, gestational diabetes, and fetal macrosomia [11]. Further research is needed into pregnancy weight-management interventions: first, to assess if these are successful, and second, to assess if weight management itself can be translated into reduced rates of cesarean delivery or morbidity. Un- 
fortunately, the studies to date have shown a modest, if any, effect [16] [17] [18]. Until appropriately powered studies with meaningful outcomes are completed, obstetric providers are limited in their ability to wisely counsel the pregnant obese population regarding risks and potential outcomes.

Limitations of our study include its observational nature and reliance on patient-reported height, weight, and pregnancy weight gain. While we were able to collect cumulative weight-gain values, we were unable to determine weight-gain patterns throughout the gestational period. However, we believe our study is an accurate reflection of common obstetric recordkeeping. As this study was conducted at a single urban institution in the United States, our data may not be generalizable to other patient populations. A strength of our study is that this was a large, modern cohort encompassing both midwifery and obstetricians' practices, and thus reflects contemporary obstetric practice.

We found that women had higher rates of primary cesarean delivery with excessive weight gain during pregnancy compared to women who adhered to Institute of Medicine guidelines. Ideally, our data could be used to advise women on the importance of weight control during pre-pregnancy counselling. Realistically, our data can be used to counsel women on the importance of modest weight gain regardless of their pre-pregnancy BMI. Adherence to guidelines for weight gain in pregnancy may potentially decrease a women's risk of primary cesarean delivery.

\section{Acknowledgements}

Presented in part at the $34^{\text {th }}$ annual meeting of the Society for Maternal Fetal Medicine, New Orleans, LA, 3-8 February 2014.

\section{Declaration of Interest}

The authors report no declaration of interest. Funding for statistical support was provided through a grant from Med Star Washington Hospital Department of Graduate Medical Education.

\section{References}

[1] Gibbons, L., Belizán, J.M., Lauer, J.A., Betrán, A.P., Merialdi, M. and Althabe, F. (2010) The Global Numbers and Costs of Additionally Needed and Unnecessary Cesarean Sections Performed per Year: Overuse as a Barrier to Universal Coverage. World Health Report, Background Paper, 30. http://www.who.int/healthsystems/topics/financing/healthreport/30C-sectioncosts. pdf

[2] Betran, A.P., Torloni, M.R., Zhang, J.J. and Gülmezoglu, A.M. (2015) WHO Statement on Cesarean Section Rates. BJOG.

[3] Martin, J.A., Hamilton, B.E., Osterman, M.J., Curtin, S.C. and Mathews, T.J. (2015) Births: Final Data for 2013. National Vital Statistics Reports, 64, 1-65.

[4] Hospital Episode Statistics Analysis, Health and Social Care Information Centre (2014) Hospital Episode Statistics: NHS Maternity Statistics-England, 2013-2014. http://www.hscic.gov.uk/catalogue/PUB16725/nhs-mate-eng-2013-14-summ-repo-r ep.pdf 
[5] Kominiarek, M.A., Vanveldhuisen, P., Hibbard, J., Landy, H., Haberman, S., Learman, L., et al. (2010) The Maternal Body Mass Index: A Strong Association with Delivery Route. American Journal of Obstetrics \& Gynecology, 203, e1-e7.

[6] Graham, L.E., Brunner, H.L.R., Thompson, M.E. and Ersel, J.L. (2014) Does Amount of Weight Gain during Pregnancy Modify the Association between Obesity and Cesarean Section Delivery? Birth, 41, 93-99. https://doi.org/10.1111/birt.12095

[7] Rasmussen, K.M. and Yaktine, A.L. (2009) Institute of Medicine (U.S.) and National Research Council (U.S.) and Committee to Reexamine IOM Pregnancy Weight Guidelines. In: Weight Gain during Pregnancy. Reexamining the Guidelines, National Academies Press, Washington DC.

[8] Norman, S.M., Tuuli, M.G., Obido, A.O., Caughey, A.B., Roehl, K.A. and Cahill, A.G. (2012) The Effects of Obesity on the First Stage of Labor. Obstetrics \& Gynecology, 120, 130-135. https://doi.org/10.1097/aog.0b013e318259589c

[9] Vahratian, A., Zhang, J., Troendle, J.F., Sciscione, A.C. and Hoffman, M.K. (2005) Labor Progression and Risk of Cesarean Delivery in Electively Induced Nulliparas. Obstetrics \& Gynecology, 105, 698-704. https://doi.org/10.1097/01.aog.0000157436.68847.3b

[10] Soni, S., Chivan, N. and Cohen, N. (2013) Effect of Maternal Body Mass Index on Oxytocin Treatment for Arrest of Dilation. Journal of Perinatal Medicine, 41, 517 521.

[11] The American College of Obstetricians and Gynecologists (2013) Committee Opinion 549: Obesity in Pregnancy. Obstetrics \& Gynecology, 121, 213-217. https://doi.org/10.1097/01.AOG.0000425667.10377.60

[12] Roofthooft, E. (2009) Anesthesia for the Morbidly Obese Parturient. Current Opinion in Anesthesiology, 22, 341-346. https://doi.org/10.1097/aco.0b013e328329a5b8

[13] Flegal, K.M., Carroll, M.D., Kit, B.K. and Ogden, C.L. (2012) Prevalence of Obesity and Trends in the Distribution of Body Mass Index among US Adults, 1999-2010. JAMA, 307, 491-497. https://doi.org/10.1001/jama.2012.39

[14] Gregory, K.D., Jackson, S., Korst, L. and Fridman, M. (2012) Cesarean versus Vaginal Delivery: Whose Risks? Whose Benefits? American Journal of Perinatology, 29, 7-18. https://doi.org/10.1055/s-0031-1285829

[15] Clark, E.A.S. and Silver, R.M. (2011) Long-Term Maternal Morbidity Associated with Repeat Cesarean Delivery. American Journal of Obstetrics \& Gynecology, 205, s2-s10.

[16] Thangaratinam, S., Rogozinsha, E., Jolly, K., Glinkowski, S., Roseboom, T., Tomlinson, J.W., et al. (2012) Effects of Interventions in Pregnancy on Maternal Weight and Obstetric Outcomes: Meta-Analysis of Randomized Evidence. BMJ, 244, e2088. https://doi.org/10.1136/bmj.e2088

[17] Harden, S.M., Beauchamp, M.R., Pitts, B.H., Nault, E.M., Davy, B.M., You, W., et al. (2014) Group-Based Lifestyle Sessions for Gestational Weight Gain Management: A Mixed Method Approach. American Journal of Health Behavior, 38, 560-569. https://doi.org/10.5993/AJHB.38.4.9

[18] Lee, A., Karpavicius, J., Gasparini, E. and Forster, D. (2012) Implementing a Diet and Exercise Program for Limiting Maternal Weight Gain in Obese Pregnant Women: A Pilot Study. Australian and New Zealand Journal of Obstetrics and Gynaecology, 52, 427-432. https://doi.org/10.1111/j.1479-828X.2012.01436.x 
Submit or recommend next manuscript to SCIRP and we will provide best service for you:

Accepting pre-submission inquiries through Email, Facebook, LinkedIn, Twitter, etc. A wide selection of journals (inclusive of 9 subjects, more than 200 journals)

Providing 24-hour high-quality service

User-friendly online submission system

Fair and swift peer-review system

Efficient typesetting and proofreading procedure

Display of the result of downloads and visits, as well as the number of cited articles Maximum dissemination of your research work

Submit your manuscript at: http://papersubmission.scirp.org/

Or contact ojog@scirp.org 